\title{
Due Professional Care, Kompleksitas Tugas, Ukuran Kantor Akuntan Publik, dan Kualitas Audit pada Kantor Akuntan Publik Medan
}

\author{
Gilbert ${ }^{1}$ \\ Fakultas Ekonomi \\ Universitas Prima Indonesia \\ Yoana Fransisca ${ }^{3}$ \\ Fakultas Ekonomi \\ Universitas Prima Indonesia
}

\author{
Georgina Cynthia Monica² \\ Fakultas Ekonomi \\ Universitas Prima Indonesia
Wilsa Road Betterment Sitepu ${ }^{4}$
Fakultas Ekonomi
Universitas Prima Indonesia

Surel : georginacynthiamonica@gmail.com

\section{ABSTRAK}

Auditor memiliki beberapa faktor internal maupun eksternal yang mempengaruhi kualitas audit. Praktik audit yang berpedoman pada norma beserta asas profesi akuntan publik yang bersifat berkaitan dan independen merupakan kualitas audit. Seorang auditor harus memiliki jiwa profesionalisme yang tinggi agar tidak terjadi kekeliruan dalam proses audit. Tujuan dilakukannya penelitian ini untuk menganalisa seberapa besar hubungan due professional care terhadap kualitas audit dan apakah kualitas audit dapat dipengaruhi oleh kompleksitas tugas dan ukuran KAP. Metode penelitian ini adalah metode sampling purposive yang datanya diperoleh melalui kuesioner yang dibagikan kepada auditor akuntan publik yang berada di Medan. Bukti yang didapat dari hasil penelitian adalah Due Professional Care dan Kompleksitas Tugas memberikan pengaruh yang signifikan terhadap Kualitas Audit. Sementara itu, Ukuran KAP tidak memiliki pengaruh signifikan terhadap Kualitas Audit.

Kata Kunci: Due Professional Care; Kompleksitas Tugas; Ukuran KAP; Kualitas Audit.

\section{Due Professional Care, Task Complexity, Public Accountinf Firm Size, and Audit Quality on Medan Public Accounting Firm}

\section{ABSTRACT}

Auditor have several internal and external factors that affect audit quality. The practice that are guided by the norm and principle of the public accountant profession that are related and independent are audit quality. An auditor must have a high professionalism spirit so that there are no error in the audit process. The purpose of this research is to analyze how big the relationship between due professional care on audit quality and whether the audit quality can be affected by the complexity of the duties and size of PAF.This research method is purposive sampling method, the data is obtained through questionnaire distributed to auditors of public accountants in Medan. Evidence obtained from the research results is Due Professional Care and Task Complexity has a significant influence on Audit Quality. Meanwhile, PAF Size doesn't have a significant effect on Audit Quality.

Keywords: Due Professional Care; Task Complexity; PAF Size; Audit Quality.

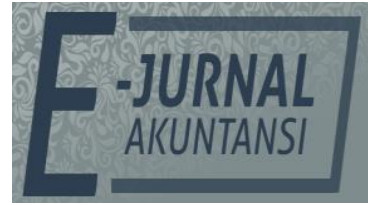

e-ISSN 2302-8556

Vol. 30 No. 12

Denpasar, Desember 2020

Hal. 3189-3198

DOI:

10.24843/EJA.2020.v30.i12.p15

PENGUTIPAN Gilbert., Monica, G.C., Fransisca, Y. \& Sitepu, W.R.B.(2020). Due Professional Care,

Kompleksitas Tugas, Ukuran Kantor Akuntan Publik, dan Kualitas Audit pada Kantor Akuntan Publik Medan. EJurnal Akuntansi, 30(12), 3189-3198

RIWAYAT ARTIKEL:

Artikel Masuk:

19 Oktober 2020 Artikel Diterima: 14 Desember 2020

Artikel dapat diakses : https://ojs.unud.ac.id/index.php/Akuntansi/index 


\section{PENDAHULUAN}

Dalam melaksanakan tugasnya, auditor memiliki beberapa faktor internal maupun eksternal yang mempengaruhi kualitas audit. Akuntan publik merupakan jasa asurans dan hasil pekerjaannya akan digunakan oleh public yang salah satunya sebagai evaluasi penting untuk mengambil keputusan yang terdapat dalam UU RI Nomor 5 Tahun 2011 tentang Akuntan Publik.

Hasil dari praktik audit yang berpatokan pada Standar Profesi Akuntan Publik (SPAP) dan norma beserta asas profesi akuntan publik yang bersifat independen merupakan kualitas audit. Terdapat beberapa faktor yang mempengaruhi kualitas audit, salah satu faktor tersebut ialah Due Professional Care. Semakin profesional auditor melaksanakan tanggung jawabnya, maka semakin kecil kemungkinan terjadinya kesalahan pada proses pengauditan. Penelitian oleh Febriyanti (2014) mengungkapkan bahwa due professional care memberikan pengaruh positif terhadap kualitas audit dimana perlu kecermatan dalam bidang tersebut sehingga akan menghasilkan kualitas yang baik juga, pendapat ini sejalan dengan Faturachman \& Nugraha (2015) yang menyatakan bahwa due professional care yang dimiliki oleh auditor senior dan junior dapat mempengaruhi kualitas audit dalam penugasan audit.

Selain itu, kompleksitas tugas juga merupakan salah satu faktor lain yang memberikan pengaruh terhadap kualitas audit. Auditor dihadapkan dengan berbagai tingkat kesulitan dan variasi tugas yang dapat mempengaruhi psikis auditor saat mengerjakannya. Penelitian yang dilakukan oleh Purnamasari \& Merkusiwati (2017) mengutarakan bahwa ketika auditor tidak mampu mengatasi banyaknya suatu tugas dan ketidakjelasan informasi akan tugas tersebut maka kualitas audit yang dihasilkan akan semakin menurun. Hasil yang sama juga ditemukan oleh Ariestanti \& Latrini (2019) yang menyatakan bahwa semakin meningkatnya kompleksitas tugas seorang auditor akan menurunkan kualitas audit seorang auditor.

Masyarakat beranggapan bahwa ukuran Kantor Akuntan Publik (KAP) akan mempengaruhi kualitas audit. Penelitian oleh Pratiwi (2017) mengutarakan bahwa ukuran KAP memberikan pengaruh negatif terhadap kualitas audit. Akan tetapi, hasil penemuan Muliawan \& Sujana (2017) mengutarakan bahwa ukuran KAP memberikan pengaruh positif terhadap kualitas audit, dimana perusahaan yang telah menggunakan jasa KAP yang berafiliasi dengan Big Four akan tetap mempertahankan kantor akuntan publik tersebut karena dianggap memiliki independensi dan memberikan kualitas audit yang lebih baik daripada KAP yang tidak berafiliasi dengan Big Four. Pendapat mengenai hubungan ukuran KAP terhadap kualitas audit ini masih menjadi perdebatan diantara para peneliti, sehingga peneliti tertarik melakukan penelitian kembali terkait ukuran KAP terhadap kualitas audit pada KAP di Medan.

Terdapat beberapa kasus yang menyebabkan menurunnya kepercayaan masyarakat terhadap auditor, salah satunya adalah kasus UU pasar modal dan norma beserta asas profesi akuntan publik dari IAPI (Institut Akuntan Publik Indonesia) yang dilanggar oleh salah satu KAP di Indonesia yaitu KAP Purwantono, Sungkoro, dan Surja. Terdapat kesalahan penyajian dan tidak adanya lampiran Perjanjian Pengikatan Jual Beli (PPJB) atas Kavling Siao Bangun (KASIBA) pada tanggal 14 Juli 2019 yang dilakukan Hanson International pada 
laporan keuangan. Akibatnya KAP tersebut dikenakan sanksi pembekuan Surat Tanda Terdaftar (STD) selama setahun.

Dari kasus tersebut, bisa disimpulkan bahwa para auditor masih banyak melakukan pelanggaran-pelanggaran. Pelanggaran tersebut akan berdampak terhadap penurunan kepercayaan masyarakat terhadap profesi akuntan publik dan mengakibatkan penurunan aktivitas pada pasar modal. Ada dua kriteria yang wajib pada diri seorang auditor, yaitu kefasihan mendeteksi kesalahan penyajian laporan keuangan dan kemampuan menghadapi variasi dan tingkat kesulitan tugas dalam proses pengauditan. Selain itu, auditor juga harus independen dalam melaporkan hasil audit meskipun auditor tersebut berasal dari ukuran KAP yang tergolong besar.

Due professional care berati melakukan evaluasi terhadap bukti audit secara kritis dan melaksanakan pemeriksaan dengan sikap teguh dan bertanggung jawab (Agoes, 2012). Selanjutnya, menurut Tugiman (2006) due professional care merupakan penerapan kecakapan dan ketelitian auditor pada saat pemeriksaan. Agustin (2013) menyimpulkan bahwa terdapat lima indeks yang dipakai untuk mengukur due professional care, yaitu ketelatenan \& keahlian bekerja; bersikap teguh menjalankan tanggung jawab; tugas dijalankan dengan berhati-hati dan mahir; berkemungkinan terjadinya kesilapan, ketidak-teraturan, \& ketidakpatuhan.

Yustrianthe (2012) menyatakan, banyak dan beragamnya tugas yang menjadikannya sulit \& membimbangkan beserta dengan terbatasnya kemahiran atau keahlian untuk menangani tugas oleh auditor disebut dengan kompleksitas tugas. Terbatasnya kemampuan, daya ingat, dan kemahiran untuk memadukan suatu masalah dapat menyebabkan tugas menjadi kompleks (Jamilah et al., 2007). Menurut William C Boynton (2002), indikator penyusunan kompleksitas tugas terdiri dari empat macam, antara lain tingkat kesukaran tugas, struktur tugas, keterangan data tidak signifikan, dan ambiguitas tinggi.

Cerminan besar kecilnya KAP dilihat dari ukuran KAP, semakin besar ukuran KAP maka hasil kualitas audit yang diperoleh akan semakin berkualitas (Arsih \& Anisykurlillah, 2015). Menurut Ginting (2014), ukuran KAP dikategorikan menjadi KAP yang beraliansi dengan Big 4 dan tidak beraliansi dengan Big 4. Ukuran KAP dapat dinilai dari berbagai hal, seperti jumlah akuntan publik dan jumlah klien pada KAP tersebut (Divianto, 2011).

Melaksanakan review secara kritis pada tingkatan-tingkatan supervise harus dilakukan oleh setiap auditor terhadap penanganan audit dan evaluasi audit sehingga kualitas auditnya akan dijaga oleh auditor (Hardiningsih \& Meita Oktaviani, 2012). Menurut Singgih \& Bawono (2010), sikap skeptis profesional selama proses pemeriksaan harus dipertahankan oleh setiap auditor, apabila auditor tidak menjaganya maka laporan keuangan yang telah diaudit tidak bisa dipercaya lagi dan memiliki kemungkinan terdapatnya gugatan paksa audit. Semakin tinggi profesionalisme auditor maka akan semakin memuaskan juga kualitas hasil pemeriksaannya (Arisanti et al., 2012). Berlandaskan uraian para peneliti maka dapat disimpulkan hipotesis sebagai berikut.

$\mathrm{H}_{1}$ : Due Professional Care memiliki pengaruh positif terhadap kualitas audit.

Menurut Tan et al., (2002), kompleksnya suatu tugas dapat menurunkan kinerja auditor yang berarti akan berpengaruh terhadap kualitas audit. Auditor 
memiliki sikap profesional yang dapat mengetahui dengan jelas tugas apa yang harus diselesaikan dan bagaimana cara menyelesaikannya sehingga tinggi rendahnya kompleksitas tugas tidak memberi pengaruh/hubungan terhadap kualitas audit (Idris \& Daljono, 2012). Setyawati (2010) menyatakan, semakin kompleks suatu tugas diharapkan akan mendorong auditor untuk melahirkan kualitas audit yang semakin bermanfaat pula. Berlandaskan uraian para peneliti maka dapat disimpulkan hipotesis sebagai berikut.

$\mathrm{H}_{2}$ : Kompleksitas Tugas memiliki pengaruh negatif terhadap kualitas audit.

Menurut Krishnan (2003) KAP besar mempunyai kualitas audit lebih bermanfaat dibanding dengan KAP kecil karena mereka memiliki tenaga ahli dalam bidang industri khusus klien dan juga memiliki insentif yang tinggi untuk menjaga reputasi mereka terhadap klien. Kualitas laporan keuangan salah satunya kualitas audit memiliki hubungan positif terhadap reputasi auditor (diukur berdasarkan ukuran KAP) (Herusetya, 2014). Menurut Pardede (2010), besar kecilnya ukuran suatu KAP bukan menjadi faktor yang memberikan pengaruh terhadap kualitas audit. Berlandaskan uraian para peneliti maka dapat disimpulkan hipotesis seperti berikut.

$\mathrm{H}_{3}$ : Ukuran KAP memiliki pengaruh positif terhadap kualitas audit.

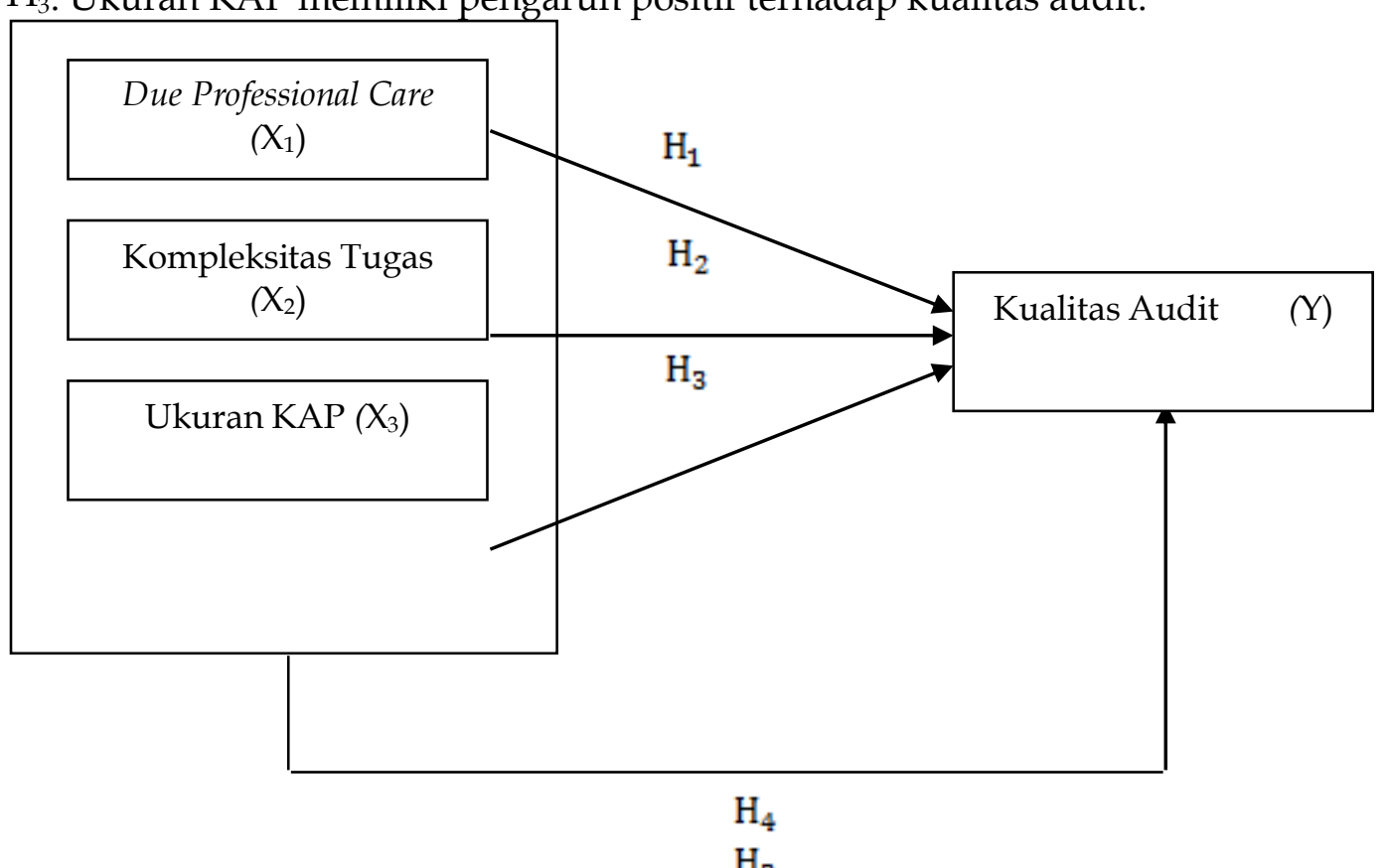

Sumber: Data Penelitian, 2020

\section{METODE PENELITIAN}

Penelitian ini dilakukan pada sembilan KAP di kota Medan yang terdaftar pada Institut Akuntan Publik Indonesia (IAPI) 2020. Obyek penelitian ini adalah Due Professional Care, Kompleksitas Tugas, dan ukuran KAP pada Kualitas Audit. Penelitian ini dilakukan dengan tujuan untuk melakukan pengujian dan menganalisis hubungan due professional care, kompleksitas tugas, dan ukuran KAP di kota Medan. Data dalam penelitian ini menggunakan data primer yang didapat dari kuesioner/angket yang dibagikan kepada para responden. Populasi dalam 
penelitian ini adalah para auditor yang bekerja pada KAP di Medan dengan sample yang ditentukan dengan metode sampling purposive dan diperoleh 80 responden.

Menurut Sugiyono (2015), untuk menjawab dan melakukan uji terhadap rumusan masalah dan hipotesis yang telah diungkapkan dapat menggunakan statistik yang sudah tersedia, teknik ini disebut dengan teknik analisis data penelitian kuantitatif. Kami menggunakan model penelitian analisis regresi linear berganda dalam penelitian ini. Secara umum, analisis regresi linear berganda dirumuskan sebagai berikut.

$$
Y=a+b_{1} X_{1}+b_{2} X_{2}+b_{3} X_{3}+\varepsilon .
$$

Dimana:

$$
\begin{array}{ll}
\mathrm{Y} & : \text { Kualitas Audit } \\
\mathrm{b}_{1}, \mathrm{~b}_{2}, \mathrm{~b}_{3} \quad \text { : koefisien regresi } \\
\mathrm{X}_{1}: \text { Due Professional Care } \\
\mathrm{a} \quad: \text { konstanta } \\
\mathrm{X}_{2} & : \text { Kompleksitas Tugas } \\
\varepsilon & : \text { error } \\
\mathrm{X}_{3} & : \text { Ukuran KAP }
\end{array}
$$

\section{HASIL DAN PEMBAHASAN}

Dalam buku Ghozali (2016) besaran yang memberikan petunjuk berapa besar pengaruh antara variabel independen terhadap variabel terikat disebut koefisien determinasi yang bernilai antara nol dan satu. Variasi variabel dependen/terikat

\begin{tabular}{|c|c|c|c|c|}
\hline \multirow[b]{2}{*}{ Model } & & \multicolumn{2}{|c|}{ Unstandardized Coefficients } & \multirow{2}{*}{$\frac{\text { Standardized Coefficients }}{\text { Beta }}$} \\
\hline & & B & Std. Error & \\
\hline \multirow{4}{*}{1} & (Constant) & 4,448 & 3,121 & \\
\hline & Due Professional Care &, 525 & ,077 & ,582 \\
\hline & Kompleksitas Tugas & ,366 & 114 & ,346 \\
\hline & Ukuran KAP & ,025 & 140 & ,022 \\
\hline
\end{tabular}
yang terbatas ditandai dengan nilai R2 yang kecil, sebaliknya jikalau nilai R2 mendekati satu maka artinya variabel bebas telah memberi seluruh informasi yang diperlukan untuk memprediksi variabel terikat.

Berdasarkan hasil analisis regresi linier berganda seperti yang disajikan pada Tabel 1, maka dapat dibuat persamaan regresi sebagai berikut.

$$
\mathrm{Y}=4,448+0,525 \mathrm{X}_{1}+0,366 \mathrm{X}_{2}+0,025 \mathrm{X}_{3}
$$

Tabel 1. Hasil Uji Analisis Regresi Linear Berganda

Sumber: Data Penelitian, 2020.

Bersumber dari tabel uji regresi linear berganda, maka dapat dijelaskan angka konstanta variabel kualitas audit adalah 4,448, ini menunjukkan apabila variabel independen (due professional care, kompleksitas tugas \& ukuran KAP) diasumsikan nol maka kualitas audit pada KAP Medan sudah menunjukkan kualitas yang sangat baik.

Angka koefisien variabel Due Professional Care adalah 0,525, hasil bertanda positif pada variabel due professional care menunjukkan bahwa apabila DPC 
semakin tinggi maka kualitas audit pada KAP di Medan akan semakin tinggi juga.

Nilai koefisien variabel kompleksitas tugas adalah 0,366 dengan hasil bertanda positif pada variabel kompleksitas tugas menunjukkan bahwa semakin kompleks suatu tugas maka akan semakin tinggi juga kualitas audit pada KAP di Medan.

Nilai koefisien variabel ukuran KAP adalah 0,025 dengan hasil bertanda positif pada variabel ukuran KAP menunjukkan dengan ukuran KAP yang semakin besar maka akan semakin tinggi juga hasil kualitas audit KAP di Medan.

Besaran yang memberikan petunjuk berapa besar pengaruh antara variabel independen terhadap variabel dependen disebut koefisien determinasi, yang bernilai antara nol dan satu (Ghozali, 2016). Adapun hasil uji koefisien determinasi hipotesis dapat dilihat pada Tabel 2.

Tabel 2. Hasil Uji Koefisien Determinasi Hipotesis $\left(\mathbf{R}^{2}\right)$

\begin{tabular}{ccccc}
\hline Model & $\mathrm{R}$ & $\mathrm{R}$ Square & Adjusted R Square & $\begin{array}{c}\text { Std. Error of the } \\
\text { Estimate }\end{array}$ \\
\hline 1 &, $844^{\mathrm{a}}$ &, 712 &, 701 & 3,325
\end{tabular}

Sumber: Data Penelitian, 2020

Bersumber dari tabel, hasil perhitungan untuk nilai $\mathrm{R}^{2}$ adalah sejumlah 0,844 atau $84,4 \%$ nilai ini membuktikan bahwa dalam penelitian, seluruh variabel independen (due professional care, kompleksitas tugas \& ukuran KAP) dapat menerangkan keberadaan variabel dependen (kualitas audit), sedangkan sisanya $15,6 \%$ merupakan faktor lain diluar dari model yang diteliti.

Agar dapat mengetahui signifikansi dan pengaruh antara variabel independen secara simultan terhadap variabel terikat dilakukanlah uji $\mathrm{F}$ yang syaratnya nilai sig $<0,05$ atau nilai F-hitung $>$ nilai F-tabel.

\section{Tabel 3. Hasil Uji F}

\begin{tabular}{|c|c|c|c|c|c|c|}
\hline \multicolumn{2}{|c|}{ Model } & Sum of Squares & Df & Mean Square & F & Sig. \\
\hline & Regression & 2081,297 & 3 & 693,766 & 62,750 &, $000^{\mathrm{b}}$ \\
\hline 1 & Residual & 840,253 & 76 & 11,056 & & \\
\hline & Total & 2921,550 & 79 & & & \\
\hline
\end{tabular}

Sumber: Data Penelitian, 2020.

Bersumber dari tabel hasil uji $\mathrm{F}$, secara simultan terdapat hubungan antara seluruh variabel independen terhadap variabel terikat dikarenakan hasil signifikansi pengaruh antara due professional care, kompleksitas tugas \& ukuran KAP secara bersama terhadap kualitas audit sebesar 0,000 $<0,05$ dan nilai Fhitung sebesar 62,750 > nilai F-tabel 2,72.

Uji parsial atau uji $\mathrm{t}$ dilakukan untuk mengetahui signifikansi masingmasing variabel independen terhadap variabel dependen. Syarat uji $t$ adalah apabila nilai sig $<0,05$ atau $\mathrm{t}$ hitung $>\mathrm{t}$ tabel, maka terdapat pengaruh antara variabel independen terhadap variabel dependen, sebaliknya apabila nilai sig $>$ 
0,05 atau $\mathrm{t}$ hitung $<\mathrm{t}$ tabel, maka tidak terdapat pengaruh antara variabel independen terhadap variabel dependen.

Bersumber dari tabel uji t, nilai sig untuk pengaruh Due Professional Care terhadap kualitas audit sebesar 0,000 < 0,05 dan nilai t-hitung sebesar 6,800 > nilai t-tabel 1,992. Hasil ini mempunyai arti bahwa secara parsial terdapat pengaruh/hubungan antara Due Professional Care terhadap kualitas audit pada KAP di Medan.

Tabel 4. Hasil Uji t

\begin{tabular}{|c|c|c|c|c|c|c|}
\hline \multirow{2}{*}{\multicolumn{2}{|c|}{ Model }} & \multicolumn{2}{|c|}{$\begin{array}{l}\text { Unstandardized } \\
\text { Coefficients }\end{array}$} & \multirow{2}{*}{$\begin{array}{l}\text { Standardized } \\
\text { Coefficients } \\
\text { Beta }\end{array}$} & \multirow[t]{2}{*}{$\mathrm{T}$} & \multirow[t]{2}{*}{ Sig. } \\
\hline & & $\mathrm{B}$ & Std. Error & & & \\
\hline \multirow{4}{*}{1} & (Constant) & 4,448 & 3,121 & & 1,425 & 158 \\
\hline & Due Professional Care & ,525 & ,077 & ,582 & 6,800 & ,000 \\
\hline & Kompleksitas Tugas & ,366 & 114 & ,346 & 3,214 & ,002 \\
\hline & Ukuran KAP & ,025 & 140 & ,022 & 180 & 858 \\
\hline
\end{tabular}

Sumber: Data Penelitian, 2020.

Selepas meninjau hasil dari uji parsial, maka dapat dinyatakan kesimpulan $\mathrm{H}_{1}$ yang menyatakan Due Professional Care memiliki pengaruh positif terhadap kualitas audit, diterima. Hasil ini mendukung beberapa penelitian sebelumnya yang dilakukan oleh Hardiningsih \& Meita Oktaviani (2012), Singgih \& Bawono (2010), dan Arisanti et al., (2012) yang membuktikan bahwa due professional care berpengaruh terhadap kualitas audit. Artinya semakin teliti auditor melakukan pengecekan kembali secara perseptif terhadap setiap proses dan pertimbangan audit maka kualitas audit yang dihasilkan akan semakin baik juga.

Berdasarkan hasil analisis, nilai sig untuk pengaruh kompleksitas tugas terhadap kualitas audit sebesar 0,002 < 0,05 dan nilai t-hitung sebesar 3,214 > nilai t-tabel 1,992. Hasil ini mempunyai arti bahwa secara parsial terdapat hubungan antara kompleksitas tugas terhadap kualitas audit pada KAP di Medan.

Selepas meninjau hasil dari uji parsial, maka dapat dinyatakan kesimpulan $\mathrm{H}_{2}$ yang menyatakan kompleksitas tugas memiliki pengaruh negatif terhadap kualitas audit, ditolak. Hasil ini mendukung penelitian sebelumnya yang dilakukan oleh Sanusi et al. (2007) dan Setyawati (2010). Artinya semakin banyak dan kompleks tugas seorang auditor, maka akan semakin banyak pengalaman yang didapatkan dalam mengerjakan tugas audit yang kemudian berdampak terhadap kualitas audit.

Berdasarkan hasil analisis, nilai sig untuk dampak ukuran KAP terhadap kualitas audit sebesar 0,858 > 0,05 dan nilai t-hitung sebesar 0,180 lebih kecil < nilai t-tabel. Hasil ini mempunyai arti bahwa secara parsial tidak terdapat hubungan antara ukuran KAP terhadap kualitas audit pada KAP di Medan.

Selepas meninjau hasil dari uji parsial, maka dapat dinyatakan kesimpulan $\mathrm{H}_{3}$ yang menyatakan ukuran KAP memiiki pengaruh positif terhadap kualitas audit, ditolak. Hasil ini mendukung penelitian sebelumnya yang dilakukan oleh Nindita \& Siregar (2012) dan Pardede (2010). Artinya pengaruh yang 
penting/berarti antara ukuran KAP dengan kualitas audit tidak terlalu terlihat, kualitas audit yang baik/tinggi tidak selalu dihasilkan oleh ukuran KAP yang besar, begitu juga sebaliknya.

\section{SIMPULAN}

Bersumber dari penelitian yang sudah kami lakukan pada KAP di Medan, maka dapat kami simpulkan bahwa due professional care, kompleksitas tugas, dan ukuran KAP secara bersama-sama memiliki pengaruh yang penting/berarti terhadap kualitas audit pada KAP di Medan. Secara parsial, due professional care dan kompleksitas tugas mempunyai pengaruh penting/berarti terhadap kualitas audit pada KAP di Medan. Sebaliknya, ukuran KAP tidak mempunyai pengaruh penting/berarti terhadap kualitas audit pada KAP di Medan.

Peneliti menyadari keterbatasan dalam melaksanakan penelitian ini dikarenakan situasi pandemi covid-19 yang menyebabkan beberapa KAP memberlakukan sistem bekerja dari rumah. Sebab itu, peneliti menyarankan untuk membuat kuesioner dengan formulir online agar dapat dibagikan kepada para auditor yang bekerja dari rumah sehingga kedepannya para peneliti selanjutnya dapat meneliti dengan seoptimal mungkin.

\section{REFERENSI}

Agoes, S. (2012). Auditing: Petunjuk Praktis Pemeriksaan Akuntan oleh Akuntan Publik. Salemba Empat.

Agustin, A. (2013). Pengaruh Pengalaman, Independensi, Dan Due Profesional Care Auditor Terhadap Kualitas Audit Laporan Keuangan Pemerintah (StudiEmpiris pada BPK-RI Perwakilan Provinsi Riau). Jurnal Akuntansi, 1(1).

Ariestanti, N. L. D., \& Latrini, M. Y. (2019). Pengaruh Kompleksitas tugas, tekanan anggaran waktu dan pengalaman auditor terhadap kualitas audit. E-Jurnal Akuntansi, 27(2), 1231-1262. https://doi.org/https:// doi.org/10.24843/EJA.2019.v27.i02.p15.

Arisanti, D., Puspa, D. F., \& Herawati. (2012). Pengaruh Independensi, Pengalaman Kerja, Due Professional Care, Akuntabilitas dan Kompetensi Terhadap Kualitas Audit. Fakulas Ekonomi Akuntansi Universitas Bung Hatta.

Arsih, L., \& Anisykurlillah, I. (2015). Pengaruh Opini Going Concern, Ukuran Kap Dan Profitabilitas Terhadap Auditor Switching. Accounting Analysis Journal, 4(3).

Divianto. (2011). Faktor-Faktor yang Mempengaruhi Perusahaan dalam Melakukan Auditor Switch. Ekonomi dan Akuntansi, 1(2), 153-173.

Faturachman, T. A., \& Nugraha, A. (2015). Pengaruh Due Professional Care Terhadap Kualitas Audit Pada Kantor Akuntan Publik Di Kota Bandung. Jurnal Riset Akuntansi dan Keuangan, 3(1), 562-571. https://doi.org/https:// doi.org/10.17509/jrak.v3i1.6604.

Febriyanti, R. (2014). Pengaruh Independensi, Due Professional Care Dan Akuntabilitas Terhadap Kualitas Audit (Studi Empiris Pada Kantor AkuntanPublik di Kota Padang danPekanbaru). Jurnal Akuntansi, 2(2). 
Ghozali, I. (2016). Aplikasi Analisis Multivariate dengan Program IBM SPSS 23. Badan Penerbit Universitas Diponegoro.

Ginting, S. (2014). Analisis Faktor-Faktor yang Mempengaruhi Pergantian Kantor Akuntan Publik pada Perusahaan Manufaktur di Bursa Efek Indonesia. Jurnal Wira Ekonomi Mikroskil: JWEM, 4(1), 1-10.

Hardiningsih, P., \& Meita Oktaviani, R. (2012). Pengaruh Due Professional Care, Etika, dan Tenur terhadap Kualitas Audit (Perspektif Expectation Theory). Seminar Nasional dan Call for Papers.

Herusetya, A. (2014). Pengaruh ukuran auditor dan spesialisasi auditor terhadap kualitas laba. Jurnal Akuntansi dan Keuangan Indonesia, 6(1), 46-70. https://doi.org/http:/ /dx.doi.org/10.21002/jaki.2009.03.

Idris, S. F., \& Daljono, D. (2012). Pengaruh Tekanan Ketaatan, Kompleksitas Tugas, Pengetahuan dan Persepsi etis terhadap Audit Judgement (studi kasus pada perwakilan BPKP provinsi DKI Jakarta) Fakultas Ekonomika dan Bisnis].

Jamilah, S., Fanani, Z., \& Chandrarin, G. (2007). Pengaruh gender, tekanan ketaatan, dan kompleksitas tugas terhadap audit judgment. Simposium Nasional Akuntansi X, 1.

Krishnan, G. V. (2003). Audit quality and the pricing of discretionary accruals. Auditing: A journal of practice $\mathcal{E}$ theory, 22(1), 109-126. http://dx.doi.org/10.2139/ssrn.320164.

Muliawan, E. K., \& Sujana, I. K. (2017). Pengaruh Ukuran Kantor Akuntan Publik, Auditor Switching dan Audit Tenure pada Kualitas Audit. EJurnal Akuntansi Universitas Udayana, 21(1), 534-561.

Nindita, C., \& Siregar, S. V. (2012). Analisis pengaruh ukuran kantor akuntan publik terhadap kualitas audit di Indonesia. Jurnal Akuntansi dan Keuangan, 14(2),

91-104. https:// doi.org/https:// doi.org/10.9744/jak.14.2.91-104.

Pardede, E. (2010). Analisis Faktor-faktor yang Mempengaruhi Kualitas Audit: Studi Empiris Perusahaan Manufaktur 2005-2008. Skripsi, Universitas Indonesia.

Pratiwi, A. (2017). Pengaruh Ukuran Kap, Fee Audit, Dan Audit Tenure Terhadap Kualitas Audit (Studi Empiris Pada Perusahaan Manufaktur yang Terdaftar Di Bursa Efek Indonesia Tahun 2011-2015) Universitas Muhammadiyah Surakarta].

Purnamasari, P. P. D., \& Merkusiwati, N. K. L. A. (2017). Pengaruh Kompleksitas Tugas, Independensi, dan Kompetensi Terhadap Kualitas Audit dengan Integritas Auditor sebagai Variabel Pemoderasi. E-Jurnal Akuntansi, 19(3), 2496-2526.

Sanusi, Z. M., Iskandar, T. M., \& Poon, J. M. (2007). Effects of goal orientation and task complexity on audit judgment performance. Management $\mathcal{E}$ Accounting Review (MAR), 6(2), 123-139.

Setyawati, Y. C. (2010). Pengaruh kompleksitas audit, pengalaman auditor dan independensi auditor terhadap kualitas audit (studi empiris pada kantor akuntan publik di jawa tengah dan Yogyakarta).

Singgih, E. M., \& Bawono, I. R. (2010). Pengaruh Independensi, Pengalaman, Due Professional Care dan Akuntabilitas Terhadap Kualitas Audit. Simposium Nasional Akuntansi XIII, 1-21. 
Sugiyono. (2015). Metode Penelitian Pendidikan Pendekatan Kuantitatif, Kualitatif, dan RED. Alfabeta.

Tan, H. T., Ng, T. B. P., \& Mak, B. W. Y. (2002). The effects of task complexity on auditors' performance: The impact of accountability and knowledge. Auditing: A journal of practice \& theory, 21(2), 81-95.

Tugiman, H. (2006). Standar Profesional Audit Internal. KANISIUS.

William C Boynton, e. a. (2002). Modern Auditing. Erlangga.

Yustrianthe, R. H. (2012). Beberapa faktor yang mempengaruhi audit judgment auditor pemerintah. Jurnal Dinamika Akuntansi, 4(2). 